\title{
DEVELOPING CONSTRUCTION DEFECT MANAGEMENT SYSTEM USING BIM TECHNOLOGY IN QUALITY INSPECTION
}

\author{
Yu-Cheng LIN, Jun-Xiong CHANG, Yu-Chih SU \\ Department of Civil Engineering, National Taipei University of Technology, \\ No. 229, No. 1. Chung-Hsiao E. Rd., Sec. 3, Taiwan
}

Received 03 Nov 2013; accepted 04 Apr 2014

\begin{abstract}
Defect management (DM) for quality inspection (QI) is a major strategy employed by general contractors to enhance construction management of building projects. However, there are significant issues in construction DM in standard practice that affects quality inspection, including protracted procedures, data entry redundancies, confusion, and inefficient information management. Recognition of these construction DM issues, this paper proposes a new and practical approach that applies Building Information Modeling (BIM) technology to quality inspection and defect management. Specifically, BIM digitally contains precise geometry and relevant data needed to support building structures to describe 3D object-oriented CAD. Using BIM technology, this study proposes a BIM-based Defect Management (BIMDM) system by on-site quality managers during the construction phase. The intended approach integrates web and BIM technologies in the BIMDM system to illustrate and analyze defect information at the jobsite in real time. The anticipated result is the effectively managed status and results of the corrective works performed. The BIMDM system is applied in a selected case study of a building project in Taiwan to verify the proposed approach and demonstrate the effectiveness of defect management practice. Utilizing the BIMDM system, on-site quality managers are better able to track and manage defects with BIM models through accurate records and photos. The combined results of the study demonstrate that a BIMDM-like system can be an effective visual defect management platform when integrating BIM and web technologies. The advantage of the BIMDM system lies not only in improving defect management efficiency for on-site quality engineers and managers, but also in facilitating easy quality inspection while identifying and communicating in the 3D BIM environment. As such, authors expect that effective use of the proposed BIMDM would significantly assist on-site quality engineers and managers to systematically handle defect management work using BIM technologies in future construction projects.
\end{abstract}

Keywords: BIM (building information modeling), information system, quality inspection, defect management.

\section{Introduction}

Defect management (DM) is a critically important strategy during the production phase in construction management. The purpose of construction DM is to discover flaws in the as-built or the assess construction quality phase that do not match the design criteria or meet the specifications. Such flaws usually include "unfinished partition corners", and "wrong cable installation" and so on. DM is typically conducted during the latter stages of construction as part of punch list checking (Dong et al. 2009). In addition, construction DM is recognized as a specific task in which mobile technologies have had limited application except in the more general area of construction progress management (Reinhardt et al. 2005). Construction DM is the process control for identifying, recording, and reporting defects that do not match the design intents (Oyedele 2011), and is now recognized as the most critical quality management strategy in construction management. The current approach to defect management results in protracted procedures and relies heavily on redundant data entry. The lack of effective design collaboration between the construction site and the off-site design office often leads to information delays in the design and construction processes, as well as confusion among different parties involved in these processes (Dong et al. 2009). Managing quality inspection (QI) work effectively can be extremely difficult in a construction building owing to unforeseen conditions and participants' comprehension level. For example, on-site quality engineers find it inconvenient to handle QI work by relying on paper-based documents. Furthermore, these engineers claim it is formidable to refer to the QI record for DM for determining the defect location based on $2 \mathrm{D}$ drawings.

Unlike in the manufacture industry, information technology is applied limitedly in construction (Boddy

Corresponding author: Yu-Cheng Lin

E-mail: yclin@ntut.edu.tw 
et al. 2007), and is mostly managed by human labor, which is inefficient and sometimes error-prone (Li, Becerik-Gerber 2011). On-site quality engineers usually refer to information such as specifications, checklists, maintenance reports, and maintenance records; however, they must record inspection (such as inventory confirmation) and QI results on hard copies in the site office. Such means of communicating information between an on-site office and a construction site are ineffective and problematic. According to the QI survey findings surrounding defect management of buildings in Taiwan (Lin 2011), the primary defect issues encountered during the construction phase are as follows: (1) lack of QI operation efficiency, especially in document-based media in the defect management QI process; (2) failure to properly manage quality defects effectively during the construction phase; (3) difficulty tracking relevant history defect information based on the tradition 2D drawings at the construction site; (4) lack of complete records provided for each defect; and (5) few effective platforms to assist on-site quality managers to improve quality inspection and defect management work effectively.

The performance of defect management can be enhanced by using BIM and web technologies to share and communicate defect information effectively. This study presents a novel approach called BIM-based Defect Management (BIMDM) system for on-site acquisition and tracking of defect and QI information in a commerce building. The BIMDM system is facilitated through the use of webcam-enabled tablets in a DM information sharing platform for on-site quality engineers and manager. Figure 1 shows applications of BIM technologies utilized for DM. The integration of BIM and web technologies improves the QI information flow in the DM process through accurate information and data entry mechanisms, thereby increasing its likelihood for effectiveness and convenience. The primary objectives of this study include (1) to apply BIM technology to increase the efficiency of QI work in the DM visualization process, (2) to integrate BIM and web technologies to link related BIM models effectively for QI and DM, and (3) to develop a web-based portal to provide wireless communication of real-time DM information between a construction site and a main office. The BIMDM system is applied to a commerce building in Taiwan to verify our proposed methodology and demonstrate the effectiveness of the defect management in a construction building. The combined results demonstrate that the BIMDM system can be a useful BIM-based QI and DM platform by integrating the BIM and web technologies.

\section{Literature review}

Limited research has examined defect management issues in construction. Battikha (2002) developed a computer-based system for construction quality management.

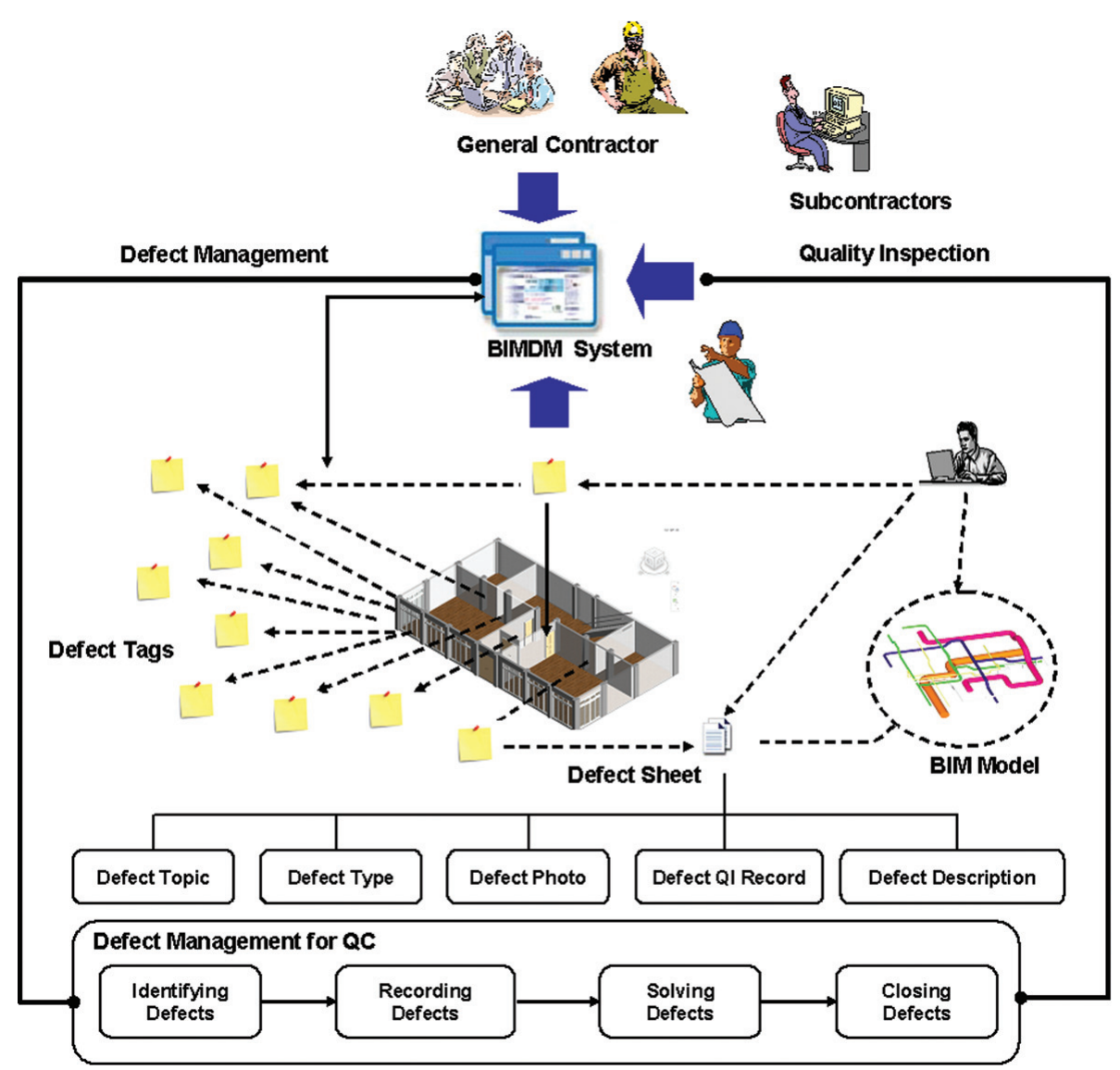

Fig. 1. Applications of BIM technologies for defect management in construction 
Kimoto et al. (2005) developed mobile computing system with personal digital assistants (PDA) for construction managers in construction sites. Wang (2008) proposed a platform for gathering, filtering, managing, monitoring and sharing quality data using Radio Frequency Identification (RFID) technology. Kim et al. (2008) proposed a computerized quality inspection and defect management system to collect defect data at a site in real time using personal digital assistant and wireless internet. Dong et al. (2009) presented a telematic digital workbench, a horizontal tabletop user interface integrating mobile computing and wireless communication to facilitate synchronous construction site to office collaboration. Park et al. (2013) presented a conceptual system framework for construction defect management using augmented reality and BIM technologies.

Building information modeling (BIM) is one of the most promising recent developments in the AEC industry (Azhar 2011). BIM digitally contains precise geometry and relevant data needed to support the design, procurement, fabrication, and construction activities to describe 3D object-oriented CAD (Eastman et al. 2011). BIM is an additional model for a project's engineering information database, storing all of the architectural designs with geometric information and the corresponding technical information for all the works (Ding et al. 2012). There are numerous previous studies that have examined BIM issues and benefits in construction. Benefits identified during the construction phase include less rework, reduction in requests for information and change orders, customer satisfaction through visualization, improved productivity in phasing and scheduling, faster and more effective construction management with easier information exchange, accurate cost estimation, and visualizing safety analysis (Eastman et al. 2011; Hardin 2009; Matta, Kam 2010; Elbeltagi, Dawood 2011; Azhar 2011; Hartmann et al. 2012). Numerous recent studies relative to information system development present the application of the proposed system integrated with BIM in construction. Vanlande et al. (2008) used IFC files to facilitate the sharing process and manage information during the entire lifecycle of an AEC project. Ricardo and Antonio (2010) proposed the SOA4BIM framework as a cloud of services that enables universal access to the BIM paradigm on the web. Jung and Joo (2011) proposed a BIM framework for evaluating promising areas and identifying driving factors for practical BIM effectiveness. Redmond et al. (2012) used cloud computing as integration platform to enhance the BIM usability experience for various disciplines in making key design decisions at the early design stage. Ren et al. (2012) presented a proposed solution to link BIM-derived data with RS Means unit price cost data to generate accurate cost estimating reports. Mill et al. (2013) provided a critical appraisal of the process of both collecting accurate survey data using a terrestrial laser scanner and creating a BIM model as the basis of a digital management model. Davies and Harty (2013) developed BIMenabled tools to allow site workers using mobile tablet personal computers to access design information and to capture work quality and progress data on-site.

Despite many articles, anecdotal information and academic literature regarding BIM issues in construction, there is a lack of evidence in support of platforms with visualization capabilities to enhance quality inspection and defect management during the latter stages of construction phase. Therefore, this study proposes a BIM-based Defect Management (BIMDM) system that integrates BIM and web technologies for use by on-site quality managers in the construction phase. By using the BIMDM system, users can quickly and automatically link the corresponding defect information to BIM models. This allows users to effectively access the defect information, solve problems, and manage defect information during the construction phase.

\section{BIM-based defect management}

Several relationships exist between defects and CAD in view of construction defect management, necessitating the engineers to manage defects linked within a CADbased environment. Therefore, the main research purpose is to develop a BIMDM system for involved engineers to facilitate defects updates and transfers within the 3D CAD environment. The proposed novel approach using BIM-based markable defects serves to enhance defect information sharing and tracking efficiency. Improving quality management, minimizing rework, and promoting beneficial change are best facilitated when participants apply the DM strategy to identify, track and manage the BIM-based markable defects. Based on literature review findings and interviews with construction professionals, the proposed DM procedure includes four phases as follows: identifying defects, recording defects, responding defects, and closing defects. Each phase is outlined briefly as follows (Table 1).

Table 1. Description of construction DM phases

\begin{tabular}{ll}
\hline Phase & \multicolumn{1}{c}{ Description } \\
\hline $\begin{array}{l}\text { Identifying } \\
\text { Defects Phase }\end{array}$ & $\begin{array}{l}\text { To identify the new or existing defect } \\
\text { issues in quality control }\end{array}$ \\
\hline $\begin{array}{l}\text { Tracking Defects } \\
\text { Phase }\end{array}$ & $\begin{array}{l}\text { To ensure that the defect is identified } \\
\text { and tracked for all related participants. }\end{array}$ \\
\hline $\begin{array}{l}\text { Solving Defects } \\
\text { Phase }\end{array}$ & $\begin{array}{l}\text { To encompass request, response } \\
\text { and tracking processes among all } \\
\text { participants. }\end{array}$ \\
\hline $\begin{array}{l}\text { Recording } \\
\text { Defects Phase }\end{array}$ & $\begin{array}{l}\text { To record the processes related to an } \\
\text { identified defect issue. }\end{array}$ \\
\hline $\begin{array}{l}\text { Closing Defects } \\
\text { Phase }\end{array}$ & $\begin{array}{l}\text { To confirm a defect issue without } \\
\text { further identification or tracking. }\end{array}$ \\
\hline
\end{tabular}


In this study, the proposed BIMDM system facilitates defect information sharing during the construction phase. The BIM technology stores the original, solving, and changed defect information, allowing all project participants to access the most recent DM information. Furthermore, BIM model can promote the sharing of electronic defects information and changes made with all project participants. The primary advantages of utilizing BIMDM system are as follows: (1) provides a simple and clear representation of defects in the 3D CAD environment; (2) illustrates solving and completed defect issues for a selected zone or floors in construction projects; (3) extends the actual defect locations as both vertical and horizontal graphic representations; and (4) helps engineers and managers track and identify defect issues through classification of defect conditions represented by different colors.

The BIM-based markable defects are designed to be easily integrated with defect issues and BIM components. The BIM-based markable defects can be defined as 3D BIM graphic representations of defect issues that link relationships between BIM components and attributes of defect issues. The BIM technology retains defect information in a digital format, facilitating easy updates and transfer of defects in the BIM environment. Assisted by the BIM technology, defect information in the BIM-based markable defect can be identified, tracked, and managed, and problems encountered during construction projects can be solved. The most recently identified defect problems and solutions can be acquired from participating engineers, and shared and saved as BIM-based markable defect units for efficient management and future reference. The proposed BIM-based markable defects contain eight components which include: the defect issue ID, topic, date, description, owner, people, attachments, and respond history.

The BIM-based markable defects, which are defined in multiple objects, are constructed from variables that can be segmented into BIM markable components in which the identified defects are stored. Defect information stored in BIM-based markable defects includes both defect problems and solutions. The BIM-based markable defects allow users to access defect information stored in layers based on defect problem attributes and type. Defect problems may consist of defect issue topics, defect issue descriptions, descriptions of problems, or defect issue attachments (e.g. documents, reports, drawings, and photos). Defect solutions may include problem descriptions, problem explanations, previous solutions, suggested solutions, and comments. The defect problems and solutions in BIM-based markable defects are associated with projects, activities, people, and organizations. Identifying the relationships between defect issues and all defect information is essential for managers and engineers when tracking and managing construction qualities. Finally, the BIM-based markable defects allow users to review BIM-based defects maps for a selected project to enhance DM effectiveness.

\section{System implementation}

\subsection{System architecture}

The conceptual system architecture is developed to underpin the BIMDM system in the study (Fig. 2). The conceptual framework of the BIMDM system content aims to improve the quality and effectiveness of BIM-based DM works. The conceptual model includes data and information on related defects, including various types of defect contents that allow flexibility and increase accessibility of the BIM-based DM process to the construction project in practice. The various defects appearing in the BIMDM system are required to be analyzed and integrated in order that a combination of contents with the functionality can support the information. The system is designed to support all features available in existing state-of-the-art DM and web communication tools. All related attachments may consist of text, photos, digital documents, and BIM models. The conceptual system architecture of BIM-based defect maps includes BIM model elements selection, BIM model viewpoint setup, BIM model location setup, and BIM model markup color setup. Furthermore, the 3D-based defect maps relationship content includes each relationship between defect content and BIM model.

The following section describes the development of the proposed BIMDM system. The BIMDM system server is based on the Microsoft Windows 2008 operating system with the SQL Server 2008 R2 as the database. The BIMDM system is developed by Microsoft Visual Basic.NET (VB.NET) programming, which is easily incorporated with ADO.NET to transact DM and BIM information with a SQL Server database. The BIMDM system consists of four different user areas - on-site quality engineer, on-site quality manager, BIM engineer, and subcontractor areas. Access to the BIMDM system

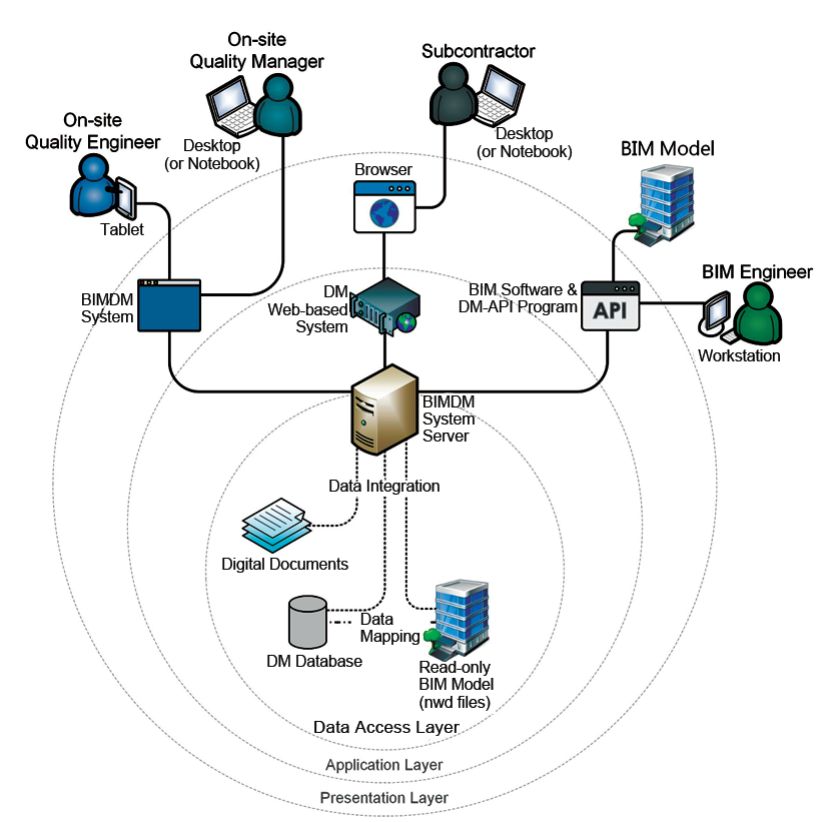

Fig. 2. System concept overview of the BIMDM system 
is password-controlled. In this study, the BIM is applied in the BIMDM system to capture and store defect information, including defect issue descriptions, defect photos, defect records, and defect reports. Autodesk Revit was used to create and maintain the BIM model files. Autodesk Navisworks was used to integrate and read the BIM models of defects. Information integration with the BIM models was achieved using the Autodesk Navisworks application programming interface (API) and VB.NET programming language. The BIMDM system was developed by integrating the BIM models of defects and DM information using Navisworks API.

\subsection{System schematic design}

The application of BIM technology through the BIM models supports on-site quality engineers in handling QI work. By clicking on BIM location maps, on-site quality engineers and manager can access the corresponding BIM model to refer defect information such as defect topic, defect detail description, defect photos, QI history information, and defect improved information. Furthermore, defects tags of the BIM model can improve traditional 2D drawings that have made it difficult to illustrate the vertical location or position of defects. Using BIM technology in this study can enhance DM work and provide detailed QI information communication. An integrated web platform can link all QI information in the building site to improve the effectiveness of the DM process.

The BIMDM system consists of a mobile devices subsystem, a DM hub center subsystem, a DM Webbased portal subsystem and a DM-API subsystem. Significantly, the mobile devices subsystem and the DM-API subsystem are located on the client side, while the DM hub center subsystem and the Web-based portal subsystem operate on the server side. Each subsystem is briefly described below.

\subsubsection{Mobile devices subsystem of BIMDM system}

There are two mobile devices used in the BIMDM system. The Acer Iconia W700P and Microsoft Surface Pro are used as the webcam-enabled tablets. Both tablets run on Windows 8 operating system. All data in the tablets are transmitted between the client and the server sides directly through the Internet via Wi-Fi or $3 \mathrm{G}$.

\subsubsection{DM hub center subsystem of BIMDM system}

The DM hub center is an information center in the BIMDM system to which all participants log onto and can immediately obtain QI information required for DM. Users can access different information and services through a single front-end on the Internet. For example, on-site quality engineers can log onto the DM hub center and securely access the latest QI result information. On-site quality managers can determine the QI status, results and various other DMrelated data. All QI-related information acquired within the DM hub center subsystem is recorded in a centralized DM database. All quality-related suppliers and subcontractor can update required QI information through the DM hub center subsystem based on their access privileges.

The QI information storage will increase over time if the entire QI information is recorded in the BIM model. Because BIM models cover a wealth of building information, system storage space should be reserved for crucial information, such as defect ID and title of defect, defect location and other critical information. In order to keep the system performance at an acceptable level, the information derived by other applications should be stored in an external location. Consequently, a DM database is developed in the BIMDM system to store related QI data and information derived by other applications. The BIM model file (NWD format) stores only basic information (such as ID and name of BIM components, and key parameter information of BIM components).

\subsubsection{DM web-based portal subsystem of BIMDM system}

The DM web-based portal subsystem is a browser-based portal in the DM system to which all subcontractors respond the solved defects problem and the responded defects result to on-site quality manager. For example, subcontractors can log onto the DM web-based portal and securely access the latest QI defect result information. The subcontractor can update the problem solved status, results and various other QI-related respond information. All QI-related problems and respond information regarding subcontractors are recorded in a centralized DM database.

\subsubsection{DM-API subsystem of BIMDM system}

The BIM model must meet the information requirement to provide all information and related models in a building site for QI operations. When the BIM models save complete building information, the BIM engineer needs only to use BIM software (such as Revit) to initially create central BIM models. The accuracy of the central BIM models is important for maintaining DM operations in the BIMDM system, and simultaneous multiple uses of the central BIM models should be avoided. Therefore, this study develops a DM-API subsystem to assist the BIM engineer in exporting the central BIM models into read-only BIM models (NWD files), and uploading them to the BIMDM system automatically. The read-only BIM models (NWD files) can be downloaded on the client side of the BIMDM system for QI and DM usage. If the central BIM model has been modified, the DM-API subsystem will synchronize the latest read-only BIM models automatically. Furthermore, all information of BIM components in the read-only BIM models (NWD files) can be saved and updated without accessing the central BIM models directly.

In the BIMDM system, four major roles are involved in DM, including BIM engineers, an on-site quality manager, on-site quality engineers, and subcontractors. To prevent the DM operation from affecting the QI operation 
of the BIM models, this study uses the client-server system architecture. In the BIMDM system, all read-only BIM models (NWD files) are stored on the server side. Additionally, only BIM engineers can access, edit and export central BIM models into BIM models (NWD files) using the DM-API subsystem directly on the server side. Conversely, the on-site quality engineers and manager refer QI information through the read-only BIM models (NWD files) and edit QI information through the DM database in the BIMDM system on the client side.

The BIMDM system server supports four distinct layers, each with its own responsibilities: management, data access, application and presentation. The following section describes the distinct layers in the BIMDM system (Fig. 3).

The management layer provides BIM engineers with tools to edit and manage BIM models. Using BIM software, BIM engineers can access and edit BIM models saved in the server through the Internet. Integrated with the DM-API subsystem, the management layer can both import and export data between the central BIM models and read-only BIM models (NWD format). Furthermore, related DM information can also be linked from the DM database in the BIMDM system management layer.

The data access layer includes the DM database and BIM models (NWD format). The DM database stores and records all detailed $\mathrm{QI}$ and $\mathrm{DM}$ records in accordance with the element ID. The BIM model (NWD format) stores complete BIM elements information in the BIM models including element ID, name, and type. Primary key establishes a relationship between element ID and the main index. Accordingly, information can be used for data association that can be applied for data mapping to retrieve complete QI and DM information based on element ID between the BIM models (NWD format) and the DM database.

The application layer defines various applications for the major system and API modules. These applications offer indexing, BIM model data updates and transfers, DM status visualization, and report generation functions. Using developed API modules, the application layer integrates BIM software used to open the BIM models.

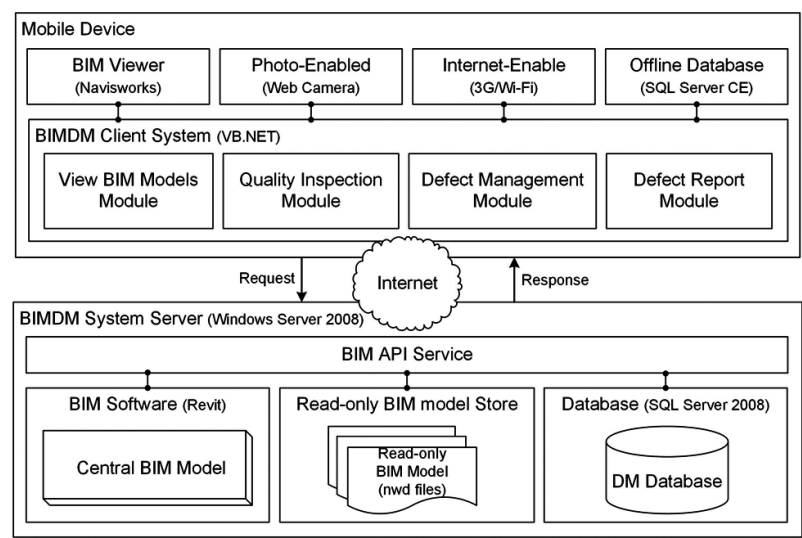

Fig. 3. System framework of the BIMDM system
Finally, the application layer can automatically conduct data acquisition, make analysis based on a request, and return the results to the client side.

The presentation layer is the main implementation platform of the BIMDM System. During the DM process, the on-site quality engineers and manager can use a tablet (client side) or desktop PC to access the BIMDM system for handling the QI work. The presentation layer displays the location information of the BIM model automatically, records QI information, illustrates different conditions and statuses of DM, queries the history, and exports reports on DM results.

\subsection{System modules}

This section demonstrates the implementation of BIMDM system modules. Figure 4 illustrates the system and modules framework of the BIMDM system.

\subsubsection{View BIM models module}

The view BIM models module provides on-site quality engineers access to view and refer BIM models at the construction site. This module enables all on-site quality engineers using a tablet to rapidly refer to information about a defect location and elements, specifically the 2D/3D location.

\subsubsection{Quality inspection module}

On-site quality engineers or manager can access and enter the most up-to-date inspection history results directly using a tablet in the QI module. Additionally, tablets display the checklist for every QI task. On-site quality engineers can record information such as dates, conditions, inspection results, descriptions of problems that have arisen, and recommendations. Furthermore, on-site quality engineers can select relevant tasks from lists in the tablet and determine those that fail inspection. The on-site quality engineers can mark the defect location using the BIM model directly, editing the defect description, and linking the defect-related digital photos. A benefit of the module is the elimination of data entry duplication by transferring inspection results and records integrated with BIM models between the tablet and BIMDM system by real-time synchronization.

\subsubsection{Defect management module}

The DM module enables the on-site quality manager to monitor the progress of quality inspections. The easily accessed module provides a portable environment in which the on-site quality manager and engineers can track and record all information regarding the status of the DM process from the tablet or BIMDM system directly.

\subsubsection{Defect report module}

Users can easily access the defect report module to identify their needs and analyze defect information according to their requirements in the BIMDM system. All inspection results can be presented with BIM models 


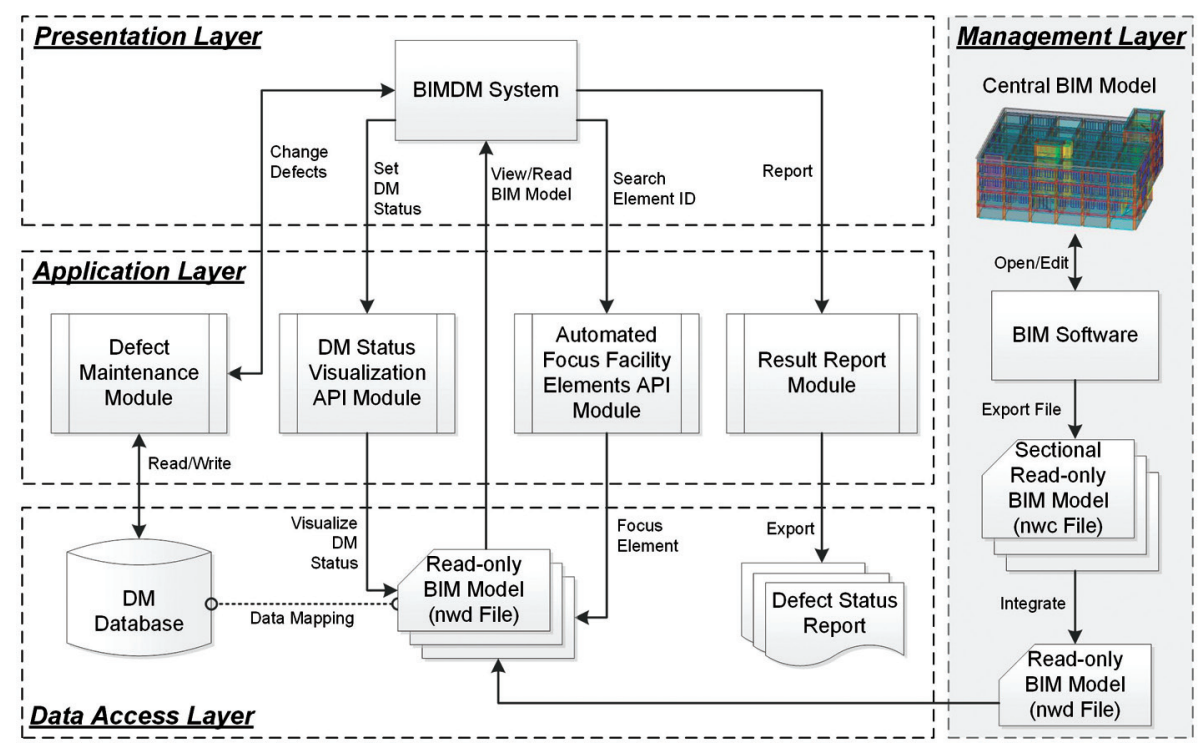

Fig. 4. System and modules framework of the BIMDM system

and extracted using commercially available software (e.g. PDF). Authorized records are maintained by general contractors and can be extracted, summarized and reported based on each defect issue.

\subsection{System initialization process description}

Upon completion of the system initialization process in the BIMDM system, on-site quality engineers and manager can view and access BIM models (NWD file), and open the monitoring API module. When handling the QI work, on-site quality engineers and manager can monitor and refer the newest state of DM reflecting varying color visualizations of BIM models through the BIMDM system.

During the QI operations, the DM status can be enhanced by color visualization in the BIM model. Color visualization enhancement is achieved through the DM status visualization API module. From the list of defects in the DM database, the BIMDM system can access the related DM status through the functionality that visually depicts the DM status for each identified defect. Furthermore, the BIM model can visualize different colors based on each DM status in the facilities. Given this design concept, more complex operating procedures of $\mathrm{DM}$ are simplified in the BIMDM system. By clicking the BIM-based defect maps, each defect form will illustrate the historical information, the status and condition of the selected defect. One of the major characteristics of the BIMDM system is to provide users an easy-to-use visualization for handling QI and DM work. The proposed approach provides an effective means to update the QI information of the BIM model and DM information synchronization. Finally, the design of system interface is modified for easy and effective application based on suggestions of the on-site quality engineers and managers. Figure 5 illustrates the system process flowchart used in the BIMDM system.

\section{System validation}

\subsection{Case study}

The following case involves a general contractor with 20 years of experience in constructing office buildings in Taiwan who was seeking to manage defects effectively and enhance quality defect management. The QI work was customarily executed by on-site quality engineers. The bulk of defect inspections work was paper-based and documented by repeated manual entry; although a defect management system had been developed for information management. This study utilizes a BIMDM system to operate DM for QI work of building projects specifically during the latter stages of the construction phase. All BIM models were developed by the general contactor. The general contractor reused the BIM models during the latter stages of construction as part of punch list checking. The main benefits included less rework and improved QI productivity. The application of BIM models during the latter stages of the construction phase enhanced defects management effectively. The on-site quality engineers and manager employed the BIMDM system to enhance defect management for quality inspection of building projects in the case study.

During the defects identification phase, project managers or responsible participants identified all of the defects. The engineer who initially identified and edited defect issues related to interior decoration defects within the BIM-based markable defects (Fig. 6a and Fig. 6b). These defects included descriptions of problems with interior decoration and defect photos. Additionally, this engineer assigned participants to identify and track defects in the BIMDM system. Finally, this engineer submitted BIM-based markable defects in the BIMDM system for approval (Fig. 6c). When the processed defect was tracked, the system showed the most recent status and result for each defect. Engineers were able to 


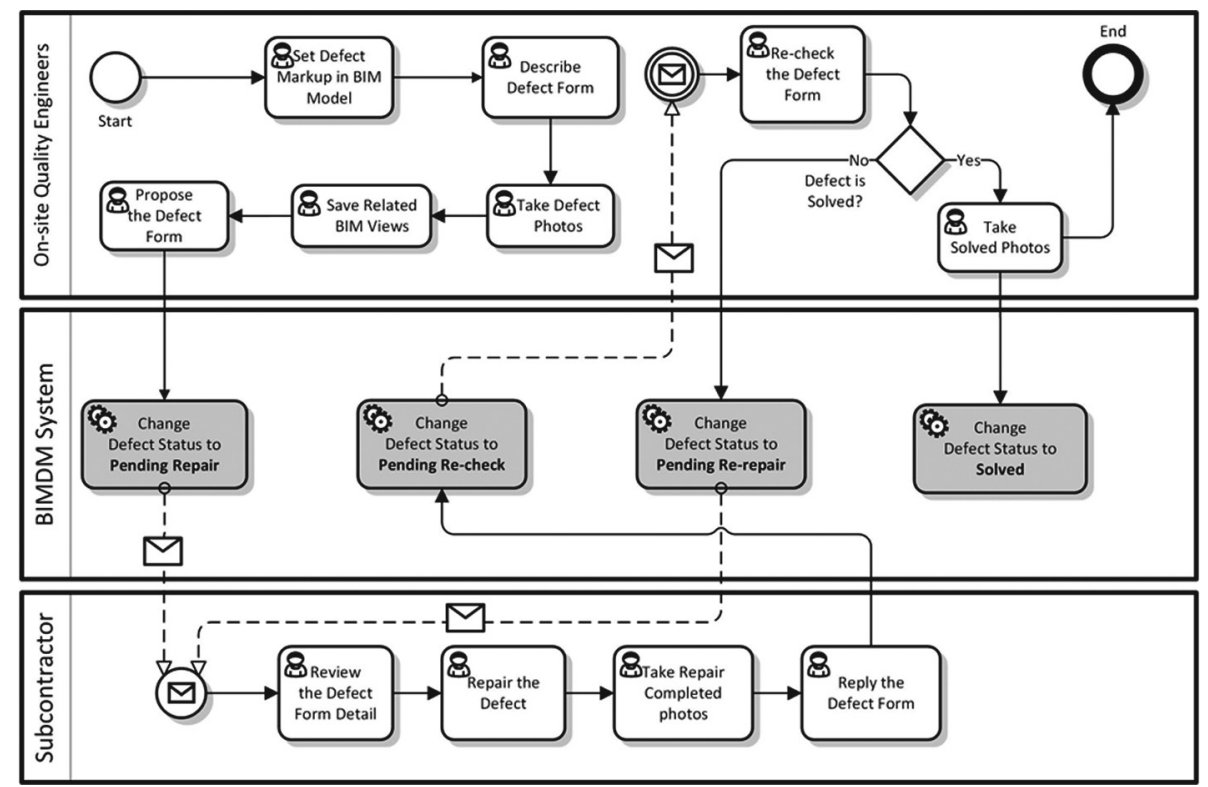

Fig. 5. The system process flowchart used in the BIMFMM system

access related defects directly by clicking on defect visual components in the BIM-based defects maps (Fig. 6d). In addition, all defects were stored in the central database to avoid redundancy. Upon approval from the project manager, related responsible participants recorded their experiences related to the interior decoration defects in the BIMDM system.

During the defects tracking phase, four engineers communicated their selected defect issues in the BIMDM system and shared the most recent defect information. This allowed parties responsible for a defect to share explanations and comments with other participants. One project manager used the BIMDM system to discuss defects with two interior decoration engineers. Another senior engineer requested responses from two interior decoration engineers associated with the defect. The engineer identified problems and noted the defects (including descriptions, digital photos, and related documentations) provided by the interior decoration engineers. During the recording and tracking phase, all records of defects processes were saved and tracked continually. Defects that lacked a response or were not processed timely were tracked in red and highlighted by the BIMDM system. Furthermore, project managers and related participants were able to track and manage all completed or processed defects during the defects responding phase. After acquiring comments and assistance from all related participants, this engineer solved the defects problem and responded to the on-site quality manager with the defects result (Fig. 6e). Figure 6f presents the on-site quality manager's defect records that were tracked and discussed.

During the defects closing phase, this engineer closed the approved and confirmed defect case. The defect status was updated and labeled as defect closure in blue in the BIMDM system after the approval process was complete. A notice and report were transmitted to the project manager and authorized participants by electronic mail.

\subsection{Field tests and results}

During the field trials, verification and validation tests were performed to evaluate the system. Verification aims to evaluate whether the system operates correctly according to the design and specification; validation assesses the usefulness of the system. The verification test was carried out by determining whether the BIMDM system could perform tasks as specified in the system analysis and design. The validation test was undertaken by asking selected participants to use the system, and provide feedback in a questionnaire. There were 24 participants involved in the evaluation test. To evaluate system function and the level of satisfaction with the system's capabilities, the users of the system were asked to assess the conditions of system testing, system function, and system capability separately, as compared with the typical paper-based defect management approach. Table 2 shows different colors representing various defect conditions in the field tests using BIM models. Some comments for future improvements to the BIMDM system were also obtained from the case participants through the user satisfaction survey. Table 3 summarizes the system evaluation results.

The overall result implies that the BIMDM system is considered to be well designed, and could improve current protracted procedures in construction quality inspection. The over $91 \%$ satisfaction rate for the defect management module indicates its usefulness in providing quality inspection support at the construction site. The $88 \%$ satisfaction rate for the quality inspection mod- 
(a) On-site quality engineer used the tablet and made defect photo integrated with BIM models in the construction site

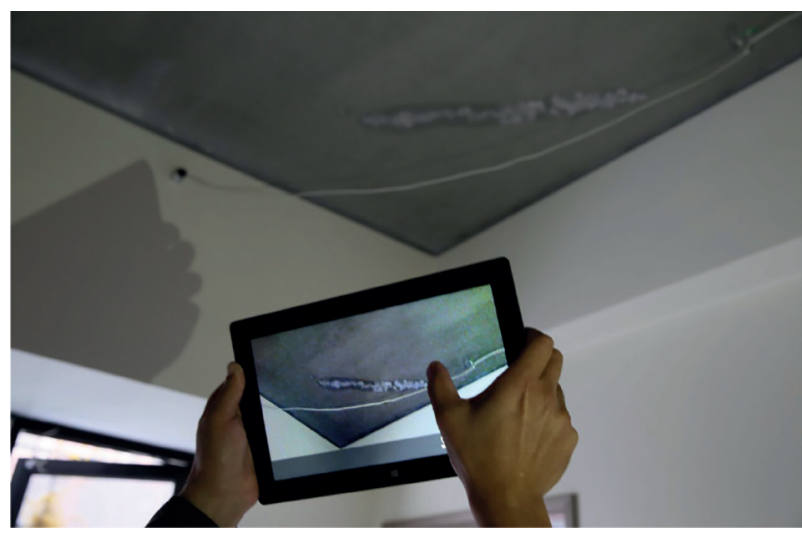

(c) On-site quality engineer inputted and updated the defect records in the tablet

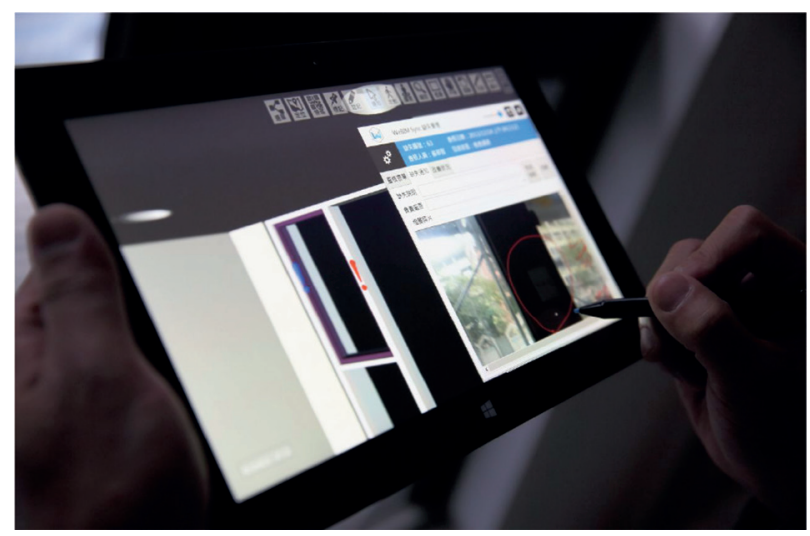

(e) The engineer solved the defects problem and responded the defects result to on-site quality manager

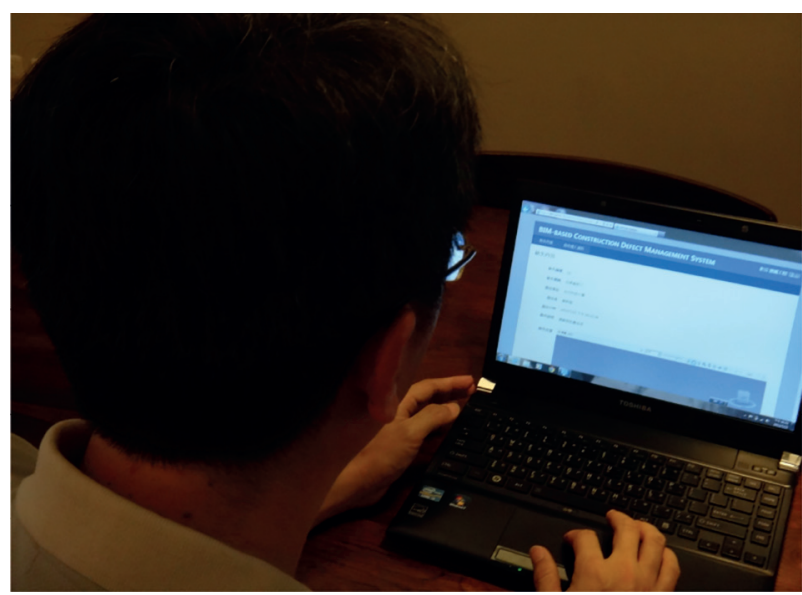

(b) On-site quality engineer marked the defect in the photo and BIM models and entered the defect records in the tablet

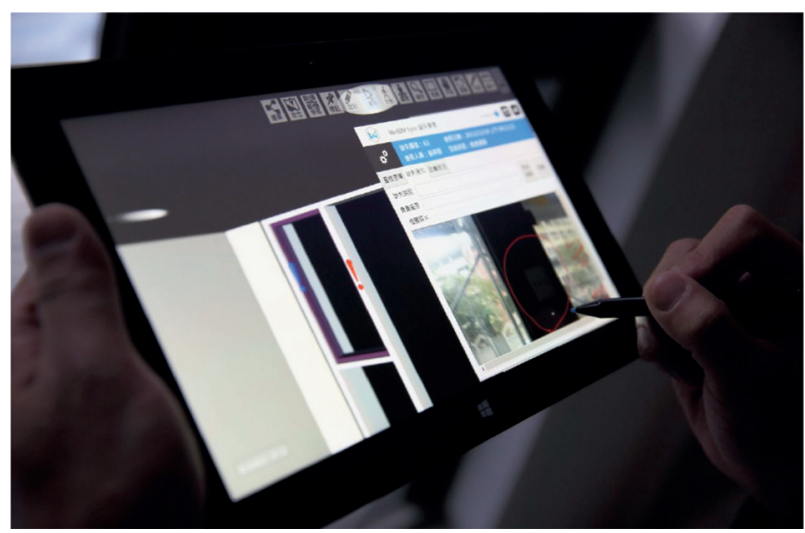

(d) On-site quality manager accessed defect records directly using BIMQI system

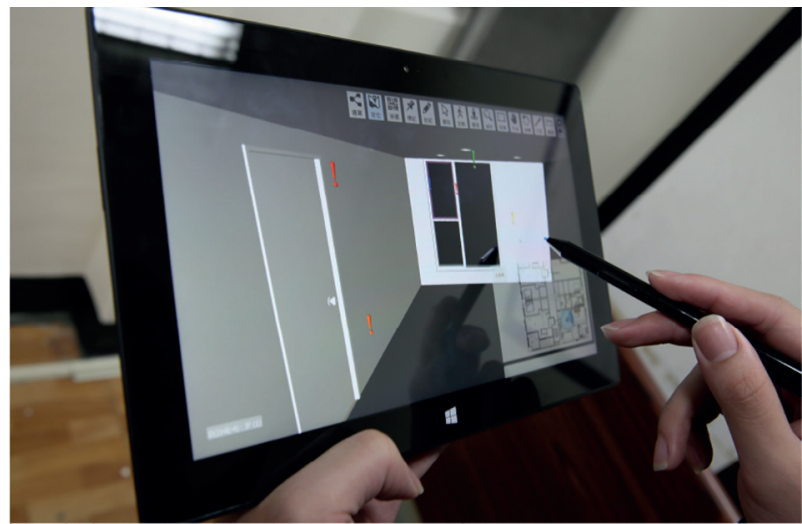

(f) On-site quality manager discussed and tracked defect records in the office

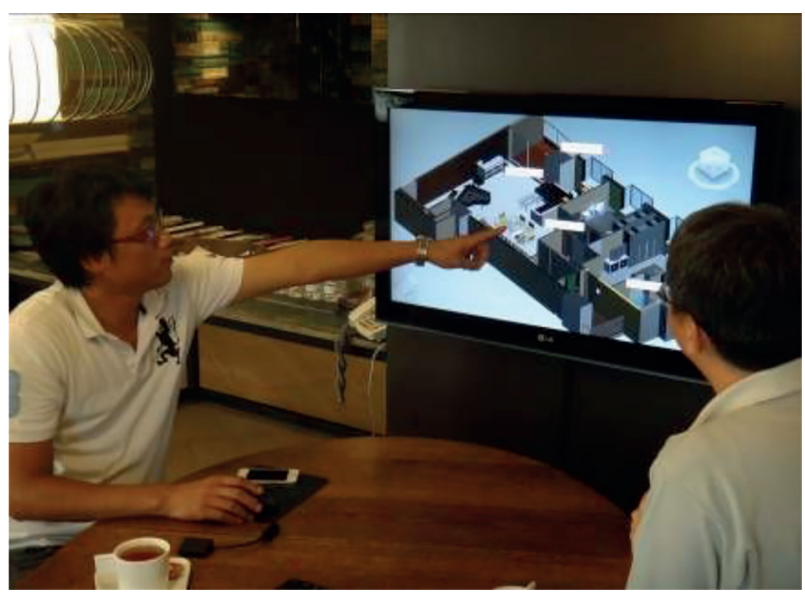

Fig. 6. On-site quality engineers and managers using webcam-enabled tablet for defect management

ule demonstrates its popularity among the on-site quality engineers who used it to access visual quality inspection directly. This module enabled engineers to communicate defect data with the BIMDM system with no additional required work needed to complete documentation beyond the data collection process. According to management survey results, monitoring and process management processes reached $85 \%$ satisfaction. Conversely, $26 \%$ of users indicated some operation difficulty with the BIM models reader (such as Autodesk Navisworks) by on-site quality engineers with which they were initially unfamiliar. The advantages and disadvantages of BIMDM system from the real case study application are identified. Finally, the case study points to the potential for visual quality 
Table 2. The application of color usage in BIMDM system

\begin{tabular}{ll}
\hline Color indicator & \multicolumn{1}{c}{ Description } \\
\hline Green color & $\begin{array}{l}\text { To index that the fault in the as-built } \\
\text { quality that did not match the design } \\
\text { requirement or meet the specifications } \\
\text { has been completed and the fixed result is } \\
\text { satisfactory. }\end{array}$ \\
\hline Red color & $\begin{array}{l}\text { To index that the fault in the as-built } \\
\text { quality that does not match the design } \\
\text { requirement or meet the specifications is } \\
\text { not yet solved. }\end{array}$ \\
\hline Blue color & $\begin{array}{l}\text { To index that the faults in the as-built } \\
\text { quality that did not match the design } \\
\text { requirement or meet the specifications is } \\
\text { solved and is awaiting for re-inspection. }\end{array}$ \\
\hline Yellow color & $\begin{array}{l}\text { To index that the fault in the as-built } \\
\text { quality that did not match the design } \\
\text { requirement or meet the specifications is } \\
\text { currently solving. }\end{array}$ \\
\hline
\end{tabular}

Table 3. System evaluation result

\begin{tabular}{lcc}
\hline System evaluation item & $\begin{array}{c}\text { Standard } \\
\text { deviation }\end{array}$ & $\begin{array}{c}\text { Average } \\
\text { rating }\end{array}$ \\
\hline Applicability to construction industry & 0.76 & 4.42 \\
\hline Ease of use & 0.55 & 4.17 \\
\hline User interface & 0.47 & 4.33 \\
\hline Overall system usefulness & 0.64 & 4.42 \\
\hline Ease of DM sharing & 0.49 & 4.58 \\
\hline Ease of locating defect information & 0.72 & 4.25 \\
\hline Improves defect problem tracking & 0.64 & 4.58 \\
\hline Reduces communication problems & 0.37 & 4.83 \\
\hline Enhances visual defect management & 0.49 & 4.58 \\
\hline Enhances defect problems illustration & 0.37 & 4.83 \\
\hline Reduces data reentry problems & 0.47 & 4.67 \\
\hline
\end{tabular}

1: Strongly disagree; 2 Disagree; 3: Neutral; 4: Agree; and 5: Strongly agree.

inspection to transform construction defect management work in practice.

Compared to the current approach, the on-site quality engineers were able to: 1) achieve a more effective performance and process; 2) experience and produce fewer errors; 3) exhibit higher levels of defects perception; 4) encounter a less confusing experience; 5) quickly perform decision-making in correcting defects; and 6) communicate with other partners easily and effectively using the BIMDM system. As well, the related participants could autonomously control the BIMDM system to access the quality inspection result remotely at the site in real-time. Experimental results demonstrate that the BIMDM system can significantly enhance defect management for the quality inspection process when using BIM technology integrated with web technology. The use of these technologies significantly enhances the overall quality inspection operation visually and effectively.

\subsection{Limitations and barriers}

Technical limitations of the current BIMDM system and inherent problems recognized during the case study are as follows:

- While using BIM technology integrated within the 3D CAD environment, successful DM implementation is compromised if BIM models are lack during the construction phase. Most of the general contractors would prefer not spending the time and associated cost using BIM strictly for DM and QI of building projects.

- The proposed approach should be modified for each building project for quality inspection and defect management. When applied to larger or special building construction cases (such as hospitals and plants, etc.), a modified approach may be required to manage the inspection unit specifications (such as in accordance with the floors). Different mark up defect information in these special buildings may produce complex illustration or difficult identification issues. Therefore, it is necessary to consider a clear and simple illustrative approach for quality inspection in construction of larger or special building types.

- The BIM model at different Level of Development (LOD) will affect the accuracy of the defect information record (such as BIM model development for tiles segmentation, kitchenware, mechanical and electrical outlet, etc.). If the BIM model LOD is insufficient, the on-site quality engineer will be unable to mark up defect problems in the actual defect location of the BIM model. Consequently, the LOD of the BIM model will need to be adjusted. However, the greater and more detail the BIM model LOD, the greater the resources will be required.

Despite these limitations, the applications of using BIM technology visualization to support synchronous construction site and off-site QI processes holds promise to transform work practices leading to reduced QI rework and improved DM effectively in the BIM environment.

\section{Conclusions}

This study presents the BIMDM system that incorporates BIM and web technologies to improve the effectiveness and convenience of QI and DM of building projects. The system also provides for synchronous communication between a construction jobsite and a jobsite office. Applied for defect management, the BIMDM system shows potential for creating new practices for the construction quality inspection and defect management in a 
BIM visualization environment. The real-time sharing of defect data integrated with BIM technology between a construction jobsite and a jobsite office in the BIMDM system may reduce redundancies, decrease poor performance, and deter a lack of common understanding among participants. During the quality inspection process, the BIMDM system improves facilities defect management efficiency on the server side by offering a hub center to provide the management division with real-time monitoring capacity. The BIMDM system provides a BIM-based visualization platform on the client side to enable on-site quality engineers the ability to seamlessly enhance quality inspection using webcam-enabled tablets at a jobsite, owing to the system's searching speed, and access to and collection of related information capabilities.

In a case study, the application of the BIMDM system helped to improve the process of quality inspection and defect management for a commerce building in Taiwan. Based on experimental results, this study demonstrated that BIM technology has significant potential to enhance quality inspection work in defect management. The integration of BIM and web technologies assisted on-site quality engineers to effectively track and control the entire quality inspection process. Compared with formerly used methods, the combined results demonstrated that the BIMDM system can be a useful BIM quality inspection and defect management platform. Although there are some challenges as indicated above, the proposed system has shown promising results and a great potential for use in equipment and facilities defect management in construction building. By integrating automatically identifying technologies, the effectiveness of quality inspection and defect management is enhanced and improved in a commerce building in Taiwan.

\section{Acknowledgement}

The authors would like to acknowledge the National Science Council, Taiwan, for financially supporting this work under contract number NSC- 102-2622-E-027011-CC3 and express our appreciation to the S.Y. Construction Inc. for its assistance in the system design, and participant interviews, and to the experts and engineers of the project owner for providing useful data, valuable information, and helpful comments during system design and development.

\section{References}

Azhar, S. 2011. Building Information Modeling (BIM): trends, benefits, risks, and challenges for the AEC industry, Leadership and Management in Engineering 11(3): 241-252. http://dx.doi.org/10.1061/(ASCE)LM.1943-5630.0000127

Battikha, M. G. 2002. QUALICON: computer-based system for construction quality management, Journal of Construction Engineering and Management 128(2): 164-173. http://dx.doi.org/10.1061/(ASCE)0733-9364(2002)128: 2(164)

Boddy, S.; Rezgui, Y.; Cooper, G.; Wetherill, M. 2007. Computer integrated construction: a review and proposals for future direction, Advances in Engineering Software 38(10): 677-687.

http://dx.doi.org/10.1016/j.advengsoft.2006.10.007

Davies, R.; Harty, C. 2013. Implementing 'Site BIM': a case study of ICT innovation on a large hospital project, Automation in Construction 30: 15-24. http://dx.doi.org/10.1016/j.autcon.2012.11.024

Ding, L. Y.; Zhou, Y.; Luo, H. B.; Wu, X. G. 2012. Using $\mathrm{nD}$ technology to develop an integrated construction management system for city rail transit construction, Automation in Construction 21(7): 64-73. http://dx.doi.org/10.1016/j.autcon.2011.05.013

Dong, A.; Maher, M. L.; Kim, M. J.; Gu, N.; Wang, X. 2009. Construction defect management using a telematic digital workbench, Automation in Construction 18(6): 814-824. http://dx.doi.org/10.1016/j.autcon.2009.03.005

Eastman, C.; Teicholz, P.; Sacks, R.; Liston, K. 2011. BIM handbook: a guide to building information modeling for owners, managers, designers, engineers and contractors. $2^{\text {nd }}$ ed. NJ: John Wiley and Sons, Ltd. 648 p.

Elbeltagi, E.; Dawood, M. 2011. Integrated visualized time control system for repetitive construction projects, Automation in Construction 20(7): 940-953. http://dx.doi.org/10.1016/j.autcon.2011.03.012

Hardin, B. 2009 BIM and construction management: proven tools, methods, and workflows. New Jersey: John Wiley \& Sons. 364 p.

Hartmann, T.; Meerveld, H. V.; Vossebeld, N.; Adriaanse, A. 2012. Aligning building information model tools and construction management methods, Automation in Construction 22: 605-613. http://dx.doi.org/10.1016/j.autcon.2011.12.011

Jung, Y.; Joo, M. 2011. Building information modelling (BIM) framework for practical implementation, Automation in Construction 20(2): 126-133. http://dx.doi.org/10.1016/j.autcon.2010.09.010

Kim, Y. S.; Oh, S. W.; Cho, Y. K.; Seo, J. W. 2008. A PDA and wireless web-integrated system for quality inspection and defect management of apartment housing projects, Automation in Construction 17(2): 163-179. http://dx.doi.org/10.1016/j.autcon.2007.03.006

Kimoto, K.; Endo, K.; Iwashita, S.; Fujiwar, M. 2005. The application of PDA as mobile computing system in construction management, Automation in Construction 14(4): 500-511. http://dx.doi.org/10.1016/j.autcon.2004.09.003

Li, N.; Becerik-Gerber, B. 2011. Life-Cycle approach for implementing RFID technology in construction: learning from academic and industry use cases, Journal of Construction Engineering and Management 137(12): 1089-1098. http://dx.doi.org/10.1061/(ASCE)CO.1943-7862.0000376

Lin, Y. C. 2011. Challenges of practical defect management for buildings during the construction phase, in Proc. of 2011 Project Management and Property Management Conference, 1 November 2011, Taipei, Taiwan. 5 p.

Matta, C.; Kam, C. 2010. The GSA's BIM pilot program. Presentation by GSA PBS Office of the Chief Architect [online], [cited 15 May 2011]. Available from Internet: http://bim.arch.gatech.edu/data/reference/gsaBIM.pdf

Mill, T.; Alt, A.; Liias, R. 2013. Combined 3D building surveying techniques - terrestrial laser scanning (TLS) and total station surveying for BIM data management purposes, Journal of Civil Engineering and Management 19(1): S23-S32. http://dx.doi.org/10.3846/13923730.2013.795187

Oyedele, O. 2011. How to manage construction defects, SciTopics [online], [cited 12 March 2013]. Available from Internet: http://www.scitopics.com/How_to_Manage Construction Defects.html

Park, C. S.; Lee, D. Y.; Kwon, O. S.; Wang, X. 2013. A framework for proactive construction defect management using 
BIM, augmented reality and ontology-based data collection template, Automation in Construction 33: 61-71. http://dx.doi.org/10.1016/j.autcon.2012.09.010

Redmond, A.; Hore, A.; Alshawi, M.; West, R. 2012. Exploring how information exchanges can be enhanced through Cloud BIM, Automation in Construction 24: 175-183. http://dx.doi.org/10.1016/j.autcon.2012.02.003

Reinhardt, J.; Garrett Jr., J. H.; Akinci, B. 2005. Framework for providing customized data representations for effective and efficient interaction with mobile computing solutions on construction sites, Journal of Computing in Civil Engineering 19(2): 109-118.

http://dx.doi.org/10.1061/(ASCE)0887-3801(2005)19:2(109)

Ren, Y.; Skibniewski, M. J.; Jiang, S. 2012. Building information modeling integrated with electronic commerce material procurement and supplier performance management system, Journal of Civil Engineering and Management 18(5): 642-654. http://dx.doi.org/10.3846/13923730.2012.719835

Ricardo, J. G.; Antonio, G. 2010. SOA4BIM: putting the building and construction industry in the Single European Information Space, Automation in Construction 19(4): 388-397. http://dx.doi.org/10.1016/j.autcon.2009.11.009

Vanlande, R.; Nicolle, C.; Cruz, C. 2008. IFC and building lifecycle management, Automation in Construction 18(1): 70-78. http://dx.doi.org/10.1016/j.autcon.2008.05.001

Wang, L. C. 2008. Enhancing construction quality inspection and management using RFID technology, Automation in Construction 17(4): 467-479.

http://dx.doi.org/10.1016/j.autcon.2007.08.005

Yu-Cheng LIN. Associate Professor of Construction Engineering and Management at the Department of Civil Engineering of the National Taipei University of Technology. He received the MS degree in the Construction Management program of Civil Engineering from the Polytechnic University, New York, USA and received PhD degree from the National Taiwan University in Taiwan (2004). He has published several articles and papers on the role of academic support service in computer-based construction project management. His current research interests include construction knowledge management, project interface management, building information modeling, web-based project management system, IT technology application, automation, BIM related topics.

Jun-Xiong CHANG. PhD candidate in the Department of Civil Engineering, National Taipei University of Technology (NTUT) in Taiwan. He received MS degree in the Construction Management program of Civil Engineering from NTUT in 2011. His published researches are centered on three areas: 1) interface management, 2) BIM management, and 3) the practices of BIM application in construction sites. His current research interests include building information modeling, construction interface management, construction management in practice, and the practice of BIM applications.

Yu-Chih SU. PhD candidate in the Department of Civil Engineering, National Taipei University of Technology (NTUT) in Taiwan. He received Bachelor's degree in Civil Engineering from NTUT in 2009. His published researches are centered on three areas: 1) BIM system applications, 2) collaboration management, and 3) RFID applications. His current research interests include management information system, construction automation integration, facility (property) management, building information modeling, and RFID applications. 